\title{
Limpieza bucodental mediante técnicas de adsorción con material desechable. Nueva alternativa de higiene oral
}

\section{Dentibuccal cleaning by adsorption techniques with disposable material. New alternative to oral hygiene}

\author{
González-González JM*
}

\section{RESUMEN}

El objetivo de este trabajo es mostrar diferentes materiales para hacer limpieza bucodental, con alto poder de adsorción, atóxicos y desechables (de usar y tirar), que masticados en la boca permitan arrastrar la placa bacteriana.

Material y métodos: Se ha seleccionado información válida para el estudio en la base de datos medline, red de internet y bibliografía de archivos propios.

Resultados: Entre los materiales hallados están: las sepiolitas, zeolitas, agares, carbón activo, polímeros de la familia de las gomas y goma arábiga, siliconas, caolín, hojas de té, cenizas de neumáticos y deshechos de plantas modificadas químicamente.

Discusión: Sepiolitas y zeolitas podrían incorporarse a gomas - tipo chicle- para ser masticados y luego desechados. Polímeros de la familia de los agares y de la familia de las gomas podrían ser aplicados sobre la superficie dental, de forma que al ser retirado pueda arrastrar la placa dental.

Conclusiones: Proponemos una nueva alternativa al cepillado dental, mediante material desechable de gran adsorción, aunque está todavía en fase de estudio y aplicabilidad en estomatología.

Palabras clave: Limpieza, bucal, dental, adsorción, material, desechable, higiene.

\section{SUMMARY}

The aim of this paper is to show different materials to make oral cleaning, with high adsorption power, nontoxic and disposable (throwaway) which chewed in the mouth allow drag plaque.

Material and Methods: valid information has been selected for study in the Medline data base, internet network and bibliography own files.

Results: Among the materials are found sepiolites, zeolites, agars, activated carbon, polymers Family gums and gum arabic, silicones, kaolin, tea leaves, tyre ashes and waste of chemically modified plants.

Discussion: Sepiolites and zeolites could be incorporated into gums - gum type - to be chewed and then discarded. Family polymers agars and gums may be applied onto the tooth surface, so that upon removal of dental plaque drag.

Conclusions: We propose a new alternative to brushing, using disposables high adsorption, although it is still under study and applicability in stomatology.

Key words: Cleaning, oral, dental, material, adsorption, disposable, hygiene.

Fecha de recepción: 14 de marzo de 2014.

Aceptado para publicación: 25 de mayo de 2014.

* Médico Estomatólogo. Doctor en Medicina y Cirugía. Práctica privada en Salamanca.

González-González JM. Limpieza bucodental mediante técnicas de adsorción con material desechable. Nueva alternativa de higiene oral. Av. Odontoestomatol 2014; 30 (6): 299-305. 


\section{INTRODUCCIÓN}

El método más empleado en la limpieza bucodental es el cepillado, complementado con un colutorio de enjuague bucal, seda dental y cepillos interproximales, entre otros.

Es conocido que algunos alimentos ofrecen mayor autolimpieza que otros. Alimentos de repostería suelen manchar mucho los dientes y favorecen la proliferación de placa. Otros en cambio, como las verduras y las frutas favorecen la limpieza, en buena parte por un fenómeno de adsorción, según el cual restos de alimentos y placa bacteriana se unen a la superficie de esos alimentos y se arrastran junto a ellos.

El propósito de este trabajo es mostrar y discutir el uso de diferentes materiales para hacer limpieza bucodental, con altos poderes de adsorción, atóxicos, desechables de un solo uso (usar y tirar) y que masticados dentro de la boca permitan arrastrar los restos de comida y placa bacteriana que puedan quedar tras una ingesta.

La placa dental está compuesta de:

- Matriz: Entramado orgánico de origen bacteriano, en el que hay restos de destrucción de bacterias y polisacáridos de cadena larga, que han sintetizado las propias bacterias a partir de azúcares de la dieta. Su función es dar sujeción, sostén y protección a las bacterias de la placa.

- Bacterias: Son de unos 200-300 tipos. Algunas, como los estreptococos (mutans, sanguis, salivaris), inician la caries al producir ácidos que desmineralizan el esmalte y la dentina. Otros, como los lactobacilos, son acidófilos y proteolíticos, desnaturalizando las proteínas de la dentina.

En la actualidad, la placa dental es considerada una biopelícula (1), entendiendo por tal una comunidad de microorganismos que crecen en una matriz de exopolisacáridos adheridos a una superficie inerte o a un tejido vivo.

La adsorción (con d) es un proceso físico o químico por el cual átomos o moléculas son atrapadas o retenidas en la superficie de un material (que suele ser sólido) (adsorbente). La absorción (con b) es, sin embargo, un proceso físico o químico en el cual átomos, moléculas o iones de una fase interpenetran en las de la otra fase para constituirse en una solución. La palabra "sorción" no especifica si es con proceso de adsorción o absorción (2) (figura 1). Factores que influyen en adsorción se hallan en la tabla 1 .

La adsorción desde una disolución a un sólido sucede por:

- El carácter liofóbico (no afinidad) del soluto respecto del disolvente.

— Una alta afinidad del soluto por el sólido.

- Por ambas dos fuerzas combinadas.

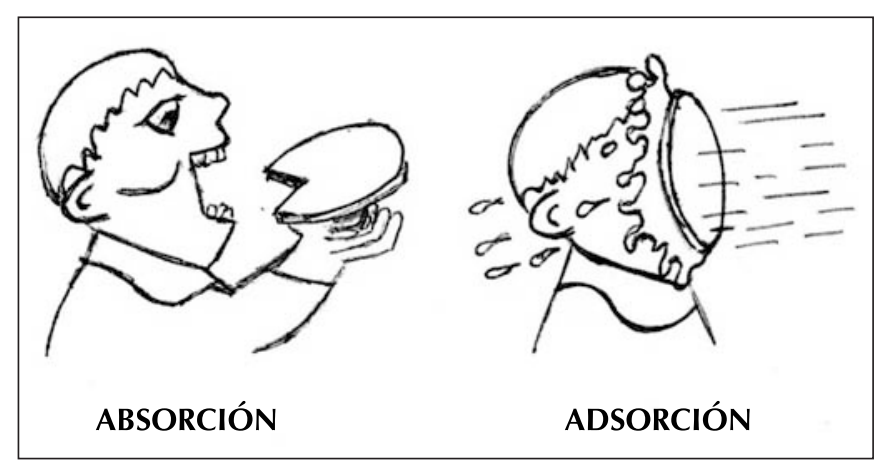

Fig. 1. Concepto de absorción y adsorción.

TABLA 1.- FACTORES QUE INFLUYEN EN LA ADSORCIÓN DE COMPUESTOS PRESENTES EN EL AGUA

- Incremento de la polaridad de la molécula.

- Tipo de compuesto: los de elevado peso molecular y baja solubilidad se adsorben más fácilmente.

- Concentración del compuesto a eliminar: cuanto más alto sea la concentración, más adsorbente se necesitará.

- Presencia de otros compuestos orgánicos que competirán por los lugares de adsorción disponibles.

- La temperatura.

- El pH del agua: ejemplo, los compuestos ácidos se eliminan más fácilmente a pH bajos. 
Cuanto mayor atracción tiene una sustancia por el disolvente más dificultad habrá para que sea adsorbida por la fase sólida.

Hay tres tipos de adsorción, según que la atracción entre el soluto y el adsorbente sea:

- De tipo eléctrico: Los iones de una sustancia ocupan una superficie debido a una atracción electrostática desde lugares cargados de la misma. La carga del ión es el factor determinante en la adsorción.

- De Van der Waals: La molécula adsorbida no está fija en un determinado lugar de la superficie, sino que está libre de trasladarse en la interfase.

- De la naturaleza química: El adsorbato tiene una interacción química con el adsorbente.

Esos tres tipos de adsorción suelen combinarse. Todos los minerales tienen cierta capacidad de cambio, pero son más acentuados en algunas especies minerales, como las "arcillas". Estas, a valores de pH normales, están cargadas negativamente, lo cual supone facilidad para adsorber cationes en su superficie. Los iones divalentes son adsorbidos más fuertemente que los monovalentes, es decir, hay mayor adsorción de cationes de mayor carga.

Las reacciones de adsorción son normalmente exotérmicas, de modo que el grado de adsorción será probablemente mayor al disminuir la temperatura, sin embargo las variaciones normales de temperatura solo tienen pequeños efectos sobre el proceso de adsorción.

En el mundo industrial, la adsorción es aplicada a la extracción de humedad del aire comprimido, haciendo pasar este por un lecho de alúmina activa hasta que se satura. También en la industria del gas natural, es empleada la adsorción para el secado, la eliminación del $\mathrm{CO}_{2}$ y para la remoción de compuestos de azufre. Se emplean en los convertidores catalíticos de los automóviles para convertir sustancias que pueden ser contaminantes atmosféricos (por ejemplo: $\mathrm{CO}$ y NO) en sustancias inocuas (por ejemplo: $\mathrm{CO}_{2}$ y $\mathrm{N}_{2}$ ). Se emplea también en las máscaras de gas para descontaminar el aire, en la purificación del vino, en la purificación de sustancias biológicamente activas como vitaminas, enzimas, hormonas y antibióticos. También en la industria de la electró- nica para estabilizar las propiedades eléctricas de dispositivos semiconductores.

\section{MATERIAL Y MÉTODOS}

Se ha hecho una selección de información válida para este estudio en la base de datos Medline, en la red de internet mediante buscadores (Google y Yahoo) y metabuscadores (Copérnico), así como en bibliografía de archivos propios. Se han seleccionado materiales de posible uso en limpieza bucodental mediante adsorción para su posterior discusión.

\section{RESULTADOS}

Entre los materiales hallados, están:

- Las sepiolitas: Son unos silicatos magnésicos hidratados con una estructura cristalina relacionada con el talco y las arcillas. Es muy poroso y recuerda a una esponja rígida, cuyo interior está atravesado por tubos huecos que hacen disminuir la densidad del mineral hasta el punto de que flote en el agua. También se la conoce por "espuma de mar" por ser la única "piedra" que flota en el agua. Tiene utilidad en trabajos de eliminación de hidrocarburos, cuando se derrama petróleo en el mar, pues la sepiolita lo adsorbe y lo mantiene flotando para permitir su retirada de modo más sencillo. Los principales yacimientos de sepiolita se hallan en Turquía, Grecia, Marruecos, España, Tanzania y Estados Unidos; sin embargo, el más importante del mundo, dada su pureza (superior al $90 \%$ ) y su magnitud (70\% de las reservas mundiales), es el depósito situado en la región de Vallecas-Vicálvaro (Madrid).

- Las zeolitas: Son minerales aluminosilicatos microporosos con alta capacidad de hidratarse y deshidratarse reversiblemente. Existen actualmente unos 206 tipos de zeolitas según su estructura, siendo la mayoría de origen sintético. Las zeolitas naturales son eficaces en la eliminación de metales pesados en exploraciones minero-metalúrgicos, como el $\mathrm{Pb}, \mathrm{Cu}, \mathrm{Ni}, \mathrm{As}, \mathrm{Cd}, \mathrm{Hg}$, Zn y se pueden obtener a bajo coste (3-5).

- Polímeros de la familia de los ágares: El agar se obtiene de las algas y es una mezcla de un poli- 
sacárido de agarosa y de moléculas más pequeñas llamadas agaropectina.

- Carbón activo: Se emplea para remover compuestos inorgánicos como As, Cd, Cr, Zn, contaminantes en la purificación del agua. Posee un gran área de superficie que permite remover contaminantes mediante fuerzas de atracción que son más altas que las que las mantienen disueltas en solución.

- Polímeros de la familia de las gomas (tipo gomas Xanthan): Muchas de ellas son comestibles de aplicación en la industria alimentaria. La goma Xanthan es un polisacárido natural de alto peso molecular, que es industrialmente producido por la fermentación de cultivos puros del microorganismo Xantomonas campestris y contiene D-glucosa y D-manosa como unidades dominantes, junto con ácido D-glucurónico. La goma Xanthan existe como un polvo de color blanco-crema, fácilmente soluble en agua caliente o fría y su función es la de actuar como coloide hidrofílico para espesar, suspender, y estabilizar emulsiones y otros sistemas basados en agua.

- Siliconas: Químicamente son muy inertes y ya curadas no son tóxicas, siendo de hecho biocompatibles (prótesis mamarias, etc).

- Goma arábiga: Polisacárido de origen natural que se extrae de la resina de árboles del género Acacia, como parte del proceso de cicatrización de estos árboles conocido como gomosis, para cerrar sus heridas y evitar así la entrada de gérmenes. Es una resina de color ámbar, recolectada normalmente a mano una vez seca. Tiene sabor neutro, es inodora, hidrosoluble y se degrada parcialmente en el intestino grueso durante la digestión. Funciona como adhesivo en muchas aplicaciones, formando delgadas películas protectoras. Es compatible con la mayoría de los aditivos y funciona como emulsivo. En productos de confitería (se halla en las gominolas, por ejemplo) la goma arábiga tiene tres funciones importantes:

- Retardar o prevenir la cristalización del azúcar.

- Emulsificar o mantener los ingredientes grasos bien distribuidos previniendo así un escurrimiento de la grasa.

- Formación de una barrera protectora contra el medio ambiente o contra la interacción de otros ingredientes.
- En otros casos, se ha sugerido el uso de caolín como antídoto en casos de intoxicación por la toma del antidiabético oral metformina (6).

- Algunos autores consideran que las hojas de té pueden ser un potencial adsorbente farmacéutico para drogas (7).

- En un estudio con cenizas de neumáticos como adsorbente se llegó a la conclusión de que podían eliminar los iones de $\mathrm{Cu}(8)$ y de $\mathrm{Hg}$ (9) de las aguas residuales, siendo además este producto de bajo coste.

- También se han empleado como adsorbentes los desechos de plantas modificadas químicamente, para la eliminación de iones de metales pesados de las aguas residuales (10).

\section{DISCUSIÓN}

Entre los materiales empleados para ayudar a retener una prótesis removible están los adhesivos dentales, que son sustancias de probada compatibilidad con los tejidos orales $(11,12)$. Sería de desear que los compuestos que hubiesen de emplearse como adsorbentes en la limpieza bucodental tuviesen al menos la biocompatibilidad de un adhesivo dental (tabla 2), sin embargo no existe un material totalmente compatible con los tejidos vivos y los que existen en el mercado se permiten por producir pocos efectos, no porque sean inocuos (13).

Sepiolitas y zeolitas son totalmente diferentes, pues mientras las zeolitas son ortosilicatos, las sepiolitas son filosilicatos. Las sepiolitas son, fundamentalmente, absorbentes y las zeolitas son, fundamentalmen-

TABLA 2.- CARACTERÍSTICAS DE UN ADHESIVO DENTAL, QUE SON DE INTERÉS EN UN MATERIAL DE LIMPIEZA POR ADSORCIÓN

- Atóxico.

- No irritante.

- Biocompatible con la mucosa.

- No permite el crecimiento bacteriano.

- Inodoro.

- Sin sabor. 
te, adsorbentes; sin embargo no son propiedades ni excluyentes ni absolutas, pues dependen de las sustancias con las que interaccionan. Ambos fenómenos, aún siendo diferentes, intervienen en mayor o menor medida en un proceso. Tanto las sepiolitas como las zeolitas podrían incorporarse como matrices a gomas tipo chicle (figura 2). La dureza de ambos materiales en la escala de Mohs (sepiolitas 2 y zeolitas 4) es menor que los 5-5.5 del esmalte, lo cual respalda su posibilidad de uso.

Para el empleo de los polímeros de la familia de los agares, una posibilidad sería enjuagarse con una emulsión de propolímero (agares) y que estos solidificasen en la boca (polimerización) por posterior enjuague con alguna disolución salina.

Respecto del carbón activo, debido a su gran poder de adsorción, ha sido empleado con eficacia en la eliminación de herbicidas (14), metales pesados (15) y pesticidas organoclorados (16) del agua, sin embargo no serviría para los propósitos expuestos en este trabajo, pues dejaría teñida de negro la superficie bucodental, añadiendo un problema más al que se trata de solucionar. El uso de carbón era una forma tradicional de limpieza de los dientes antes de la existencia de los dentífricos (17) y hoy se ha convertido en una moda "naturista" de la "vida sana".

En otros casos se ha empleado celulosa como material de adsorción para eliminar el arsénico de soluciones (18).

En cuanto a la aplicación de los polímeros de la familia de las gomas, el proceso a emplear podría ser

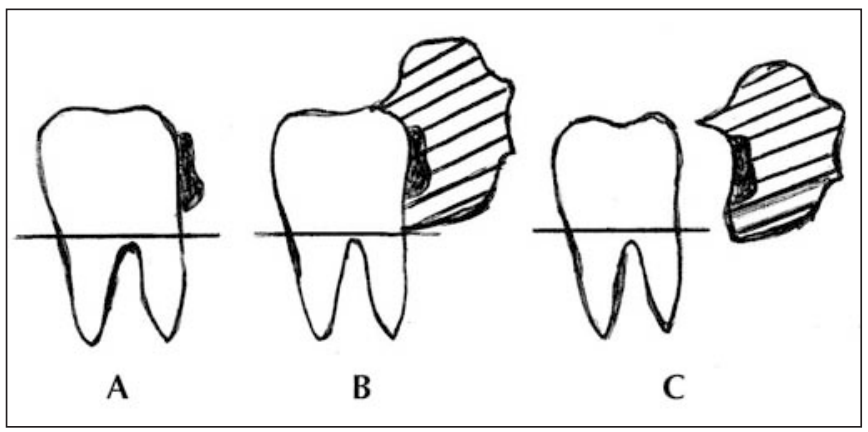

Fig. 2. La placa dental sobre el diente (A) se une a un material adsorbible (B) durante la masticación y se elimina con él (C). similar al usado en cosmética en tratamientos tipo "peeling", como las mascarillas faciales. Se trataría de que una emulsión de goma polimerice por la acción de la humedad de la boca, solidificándose hasta formar una segunda capa elástica que puede fácilmente despegarse, arrastrando impurezas de la superficie dental, las cuales quedan atrapadas en el seno de la goma. Algunas formas de posible aplicación de las gomas podrían ser:

- Rellenar un molde de resina con una goma, en forma de crema. Cuando se aplica al paciente la suciedad quedaría atrapada en su interior. Luego se retiraría el molde y posteriormente el bloque de goma solidificada. Podríamos llamarlo "efecto matriz".

- Otra posibilidad es que la goma sea aplicada sobre un papel o una fina capa de plástico y que tenga "tack" (es decir, propiedad de los adhesivos y de las pinturas en proceso de secado que consiste en un tacto pegajoso. Ejemplo: los PosIt). Se rodearía la dentadura con la lámina y luego se retiraría. Llamaríamos a esto "efecto tack". Un aspecto muy importante es que estas gomas polimerizan (solidifican) con el agua.

Una buena referencia podría ser los cosméticos que se aplican con fines similares sobre la piel, pero para el caso de la boca habría que valorar su aplicabilidad sobre la superficie oral más húmeda.

Ya se ha fabricado chicles para higiene dental con algunas características interesantes (tabla 3) aunque, a nuestro entender, no mantienen como principal aspecto el de adsorción, que es lo que buscamos.

Finalmente, queremos destacar algunas posibilidades en fase de estudio y aplicabilidad en estomatología, que podrían ser una alternativa al cepillado en la higiene dental. Nos referimos al uso de productos con alta capacidad de adsorción, del tipo de las sepiolitas y zeolitas, que podrían ir incorporados a gomas tipo chicle y que una vez masticados podrían ser desechados con evidente arrastre y eliminación de la placa dental. Algunos otros productos con igual interés podrían ser polímeros de la familia de los agares y de la familia de las gomas, que pueden ser empleados mediante una técnica de aplicación sobre la superficie dental y posterior eliminación de 


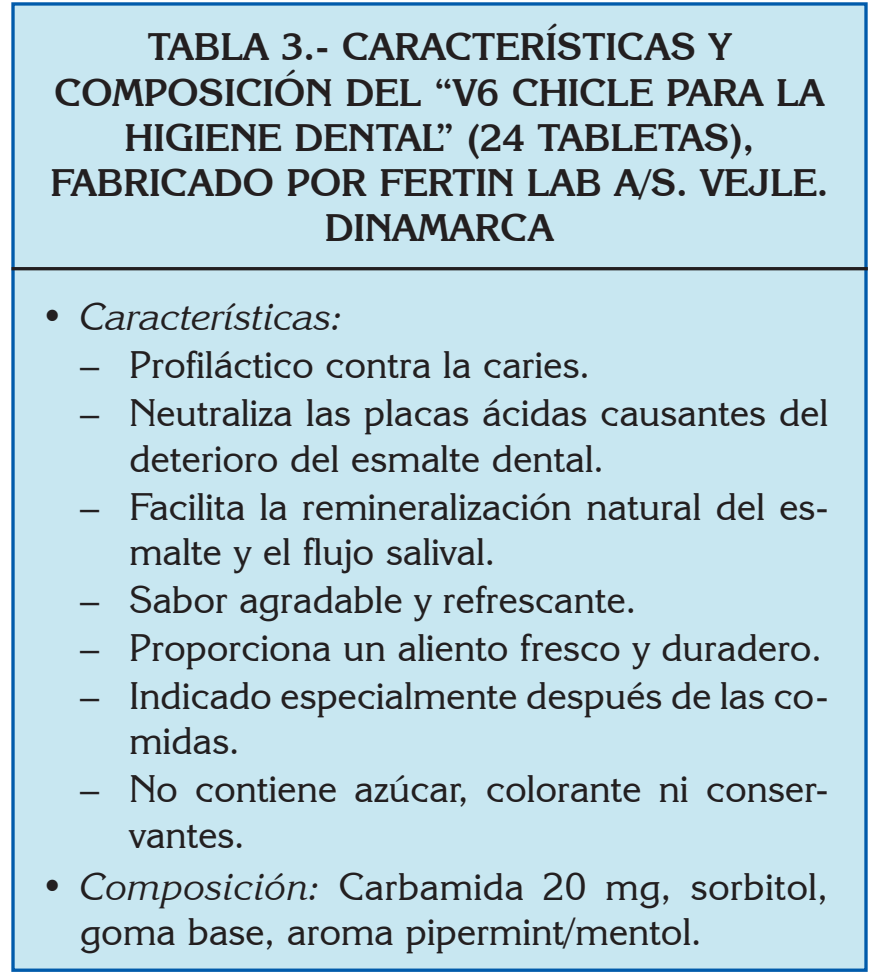

dicho producto con el consiguiente arrastre de la placa dental.

\section{AGRADECIMIENTOS}

A D. Eugenio Dorao Herrero. Químico. Burgos, por su colaboración.

\section{BIBLIOGRAFÍA}

1. Díaz Caballero AJ, Vivas Reyes R, Puerta L, Ahumedo Monterrosa M, Arévalo Tovar L, Cabrales Salgado R et al. Biopelículas como expresión del mecanismo de quórum sensing: una revisión. Av. Periodon. Implantol 2011;23(3):195-201.

2. "Adsorption". Encyclopaedia Britannica Deluxe Edition. Chicago: Encyclopaedia Britannica; 2010.

3. MS Al-Sewailem. Characteristics of Lead Sorption by Zeolite Minerals. Journal of Applied Sciences 2007;7(13):1679-98.
4. Adilson Curi, Wilmer JV Granda, Hernani M Lima, Wilson T Sousa. Las Zeolitas y su Aplicación en la Descontaminación de Efluentes Mineros. Información Tecnológica 2006;17(6):111-8.

5. MD Salim, Yukihiro Munekage, Kyaw Min Naing. Arsenic (III) removal from contaminated water using silica ceramic: A batch adsorption study. Journal of Applied Sciences 2007;7(16):231420.

6. Reem Adham Al-Bayati. Adsorption - Desorption isotherm of one of antidibetic drug from aqueous solutions on some pharmaceutical adsorbents. European Journal of Scientific Research 2010;40 (4):580.

7. Neelam Seedher, Karamvir Sidhu. Studies on the use of tea leaves as pharmaceutical adsorbent. International Journal of Biological Chemistry 2007;1(13)162-7.

8. Hassan Zavvar Mousavi, Abdorrahman Hosseinifar, Vahdat Jahed. Removal of Cu (II) from wastewater by waste tire rubber ash. J Serb Chem Soc 2010; 75(6):845-53.

9. Panu Danwanichakul, Duangkamol Danwanichakul. Mass transfer analysis of mercury (II) removal from contaminated water by non-porous waste tire granules. European Journal of Scientific Research 2009;36(3):363.

10. Wan Ngah WS, Hanafiah MA. Removal of heavy metal ions from wastewater by chemically modified plant wastes as adsorbents: A review. Bioresource Technology 2008:99(10):3935-48.

11. Adisman K. El uso de adhesivos dentales como ayuda al tratamiento protético. J. Prostht. Dent 1989;62:711-5.

12. Valle Rodríguez C, Godoy Rico L, García Evans O, Pradies Ramiro G. Adhesivos para prótesis completas: situación actual. RCOE 2007;12(4): 273-82.

13. Restrepo Ospina DP, Ardila Medina CM. Reacciones adversas ocasionadas por los biomateriales 
usados en prostodoncia. Av. Odontoestomatol 2010;26(1):19-30.

14. Rojas Moreno FJ, Cardenete López JM, Marín Galvín R, Martínez Cordón MJ, Rodríguez Mellado $\mathrm{JM}$. On the removal of s-triazine herbicides from waters using commercial low-cost granular carbons. J Serb Chem Soc 2010;75(3):299-305.

15. Mamba G, Mbianda Y, Govender PP, Mamba BB, Krause RW. Application of multiwalled carbon nanotube-cyclodextrin polymers in the removal of heavy metals from water. Journal of Applied Sciences 2010;10(11):940-9.

16. Ninkovic MB, Petrovic RD, Lauševic MD. Removal of organochlorine pesticides from water using virgin and regenerated granular activated carbon. J Serb Chem Soc 2010;75(4)565-73.
17. Dubarran R. Blanquear los dientes con carbón vegetal [citado 10 dic. 2013]. http://prosaludy bellezanaturalnatural.blogspot.com.es/2013/07/ blanquear-los-dientes-con-carbon-vegetal.html.

18. Abbas Rezaee, Gholamreza Asadikaram, Mohammad Mirzai, Nayera Naimi, Rosa Dargahi, Abbas Sadegi. Removal of arsenic using acetobacter xylinum cellulose. Journal of Biological Sciences 20088(1):209-12.

\section{CORRESPONDENCIA}

Jesús M. González-González

Ávila, $4,1^{\circ} \mathrm{A}$

37004 Salamanca

Correo electrónico: gongonjm@hotmail.com 